\title{
A Química da sobrevivência
}

\author{
João Avó \\ LAQV-REQUIMTE, Departamento de Química, FCT-UNL, Campus de Caparica, Portugal \\ jma17142@campus.fct.unl.pt
}

\begin{abstract}
Survival Chemistry - Recently, the world has assisted to an increase in natural disasters, epidemic outbreaks and military conflicts involving several nations. These events threaten the stability of society as we know it and the idea of facing a post-apocalyptic scenario during the $21^{\text {st }}$ century keeps gaining more supporters. In such a situation, basic chemistry knowledge can make the difference between life and death. In this article, some procedures that would allow one to obtain energy, light a fire or build self-defense weapons from widely available reagents and materials are described.
\end{abstract}

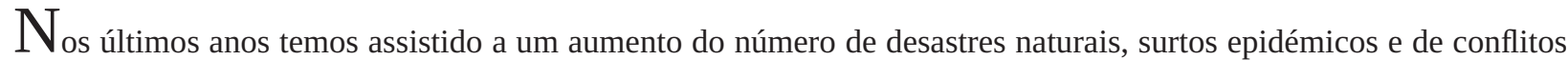
militares em larga escala. Estes acontecimentos ameaçam a integridade da infraestrutura que suporta as nossas vidas em sociedade, e a ideia de que teremos de enfrentar um cenário pós-apocalíptico durante este século ganha cada vez mais adeptos. Em tal situação, alguns conhecimentos básicos de química poderão fazer a diferença entre a vida e a morte. Neste artigo estão descritos alguns procedimentos que permitem obter energia, atear um fogo ou fazer armas de defesa com reagentes e materiais abundantes fora do laboratório.
\end{abstract}

\section{Introdução}

Desde o início do século, já assistimos a um número elevado de desastres naturais que deixaram milhares sem casa. Ocorreram, também, novos surtos de vírus que vitimaram milhares de pessoas. Para além disso, a crescente tensão sentida no Médio Oriente ameaça o equilíbrio da paz mundial e, convenhamos, a recente eleição de Donald Trump para a Casa Branca não parece estar a acalmar os ânimos. Tudo isto serve de fonte de inspiração para um número cada vez maior de obras de ficção onde são retratados cenários pós-apocalípticos, e a ideia de que este é o século em que assistiremos ao colapso da sociedade tal como a conhecemos parece estar a ganhar cada vez mais adeptos. Independentemente das causas, todos estes cenários partilham traços em comum, tais como a ausência de serviços de fornecimento de energia e água potável, escassez de alimentos e o perigo constante de ataques de outros grupos de sobreviventes. Quer se acredite ou não que isto seja possível, diz o povo que "homem prevenido vale por dois”, pelo que conhecimentos básicos de química poderão desempenhar um papel importante e ser mesmo essenciais para a sobrevivência em situações extremas.

Neste artigo serão descritos alguns procedimentos que poderiam fazer de nós verdadeiros MacGyvers, permitindo-nos obter energia, atear um fogo, purificar água ou fabricar armas de defesa com materiais e produtos que utilizamos diariamente e que poderiam ser encontrados num cenário pós-apocalíptico.

\section{Fogo sem fonte de ignição}

Sem dúvida que a capacidade de fazer fogo pode fazer a diferença entre a vida e a morte, permitindo cozinhar alimentos, tornar a água potável ou simplesmente manter ou elevar a temperatura corporal. Já dizia Bruce Springsteen no seu tema "Dancing in the Dark" que não é possível começar um fogo sem uma faísca. Mas Springsteen não é

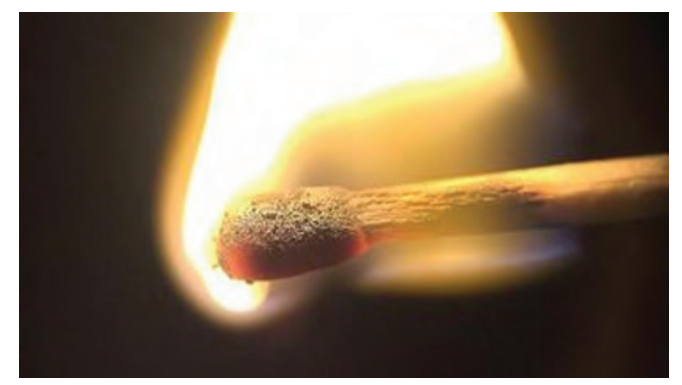

Figura 1 - Fósforo aceso pronto a atear uma fogueira

um químico, senão saberia que existem reações que podem resultar na combustão "espontânea" dos seus reagentes ou produtos sem necessitar de uma fonte de ignição externa. Algumas destas reações são mesmo utilizadas para acender uma fogueira em condições de elevada humidade ou chuva onde utensílios e técnicas mais comuns, como o uso de um sílex ou a fricção de ramos, não resultam.

A grande maioria destes processos envolve a utilização de um agente fortemente oxidante com compostos orgânicos com grupos éter (R-O-R) ou hidroxilo (R-OH). A oxidação leva à formação de produtos voláteis que, devido ao caráter fortemente exotérmico da reação, entram em combustão.

\section{Permanganato e glicerol}

Um exemplo bem conhecido pelos entusiastas da sobrevivência é a mistura do permanganato de potássio $\left(\mathrm{KMnO}_{4}\right)$ com glicerol ou etilenoglicol. Nesta reação o permanganato oxida o composto orgânico, com libertação de energia, provocando a sua combustão [1].

$14 \mathrm{KMnO}_{4}+4 \mathrm{C}_{3} \mathrm{H}_{5}(\mathrm{OH})_{3} \rightarrow 7 \mathrm{~K}_{2} \mathrm{CO}_{3}+7 \mathrm{Mn}_{2} \mathrm{O}_{3}+5 \mathrm{CO}_{2}+16 \mathrm{H}_{2} \mathrm{O}$

\section{Material e reagentes:}

- Permanganato de potássio $\left(\mathrm{KMnO}_{4}\right)$

- Glicerol $\left(\mathrm{C}_{3} \mathrm{H}_{5}(\mathrm{OH})_{3}\right)$ ou etilenoglicol $\left(\mathrm{HOCH}_{2} \mathrm{CH}_{2} \mathrm{OH}\right)$

- Folha de alumínio 


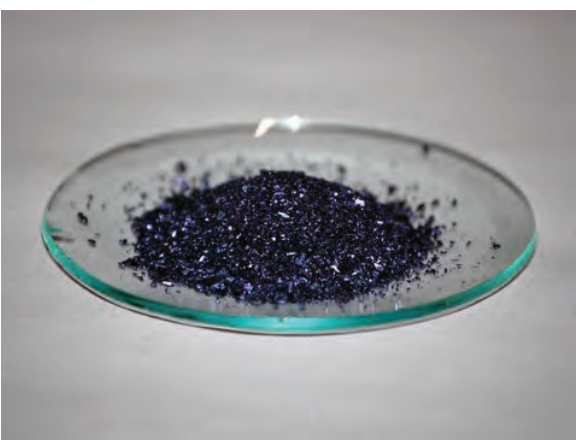

Figura 2 - Vidro de relógio com cristais de permanganato de potássio

\section{Procedimento:}

- Colocar uma porção de $\mathrm{KMnO}_{4}$ (aprox. 1 colher de sopa) num pedaço de folha de alumínio.

- Adicionar um volume igual de glicerol de modo a cobrir todo o permanganato.

- Aguardar até que se verifique a formação de uma chama. O tempo pode variar de alguns segundos até um minuto, dependendo do tamanho dos cristais de permanganato utilizados.

\section{Onde encontrar os reagentes:}

O permanganato de potássio é comum em kits de sobrevivência devido à sua utilidade para acender fogos, bem como um desinfetante para água ou como corante para sinais de SOS na neve. Em lojas de bricolage e jardim pode ser encontrado nas secções dedicadas ao tratamento de águas. Tanto o glicerol como o etilenoglicol podem ser encontrados na maioria das drogarias e lojas de bricolage ou de artigos de automóvel. O primeiro é vendido como glicerina e é utilizado como lubrificante em aplicações diversas. O segundo é vendido principalmente como anticongelante.

\section{Hipoclorito e etilenoglicol}

O hipoclorito de cálcio é um agente fortemente oxidante que se utiliza geralmente como desinfetante de piscinas. A sua utilização para atear fogos tem ganho popularidade entre os internautas devido à sua espontaneidade e efeito visual, e não são raros os vídeos em que os "atores" chegam mesmo a ficar sem sobrancelhas.

Tal como no exemplo anterior, esta reação envolve a mistura de um agente oxidante com compostos orgânicos hidroxilados (etilenoglicol, por exemplo). Acredita-se que o hipoclorito promova a formação de um radical alcóxido que rapidamente decai com a degradação da cadeia do diol, dando origem a compostos voláteis inflamáveis e a um aumento rápido de temperatura (esquema 1) [2].

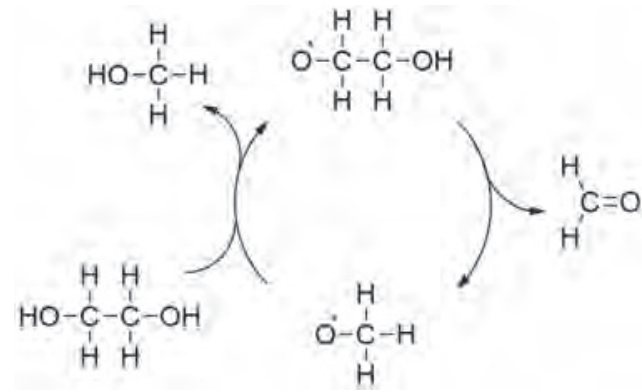

Esquema 1 - Mecanismo proposto para a degradação de etilenoglicol por ação do hipoclorito de cálcio

\section{Material e reagentes:}

- Hipoclorito de cálcio $\left(\mathrm{Ca}(\mathrm{ClO})_{2}\right)$

- Etilenoglicol

- Recipiente metálico ou papel de alumínio

\section{Procedimento:}

- Colocar uma porção de $\mathrm{Ca}(\mathrm{ClO})_{2}$ (aprox. 1 colher de sopa) num pedaço de folha de alumínio ou num recipiente metálico de boca larga.

- Adicionar 20 a $50 \mathrm{~mL}$ do reagente orgânico. A reação deverá ocorrer em poucos segundos.

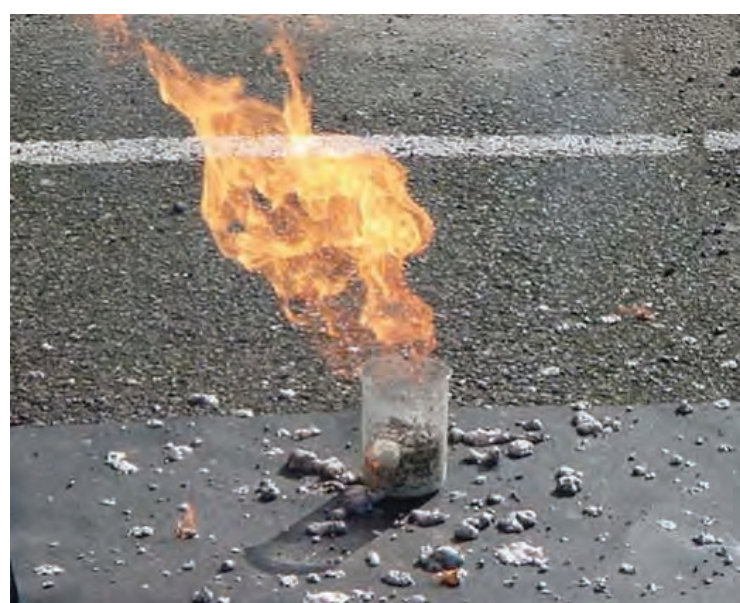

Figura 3 - Recipiente com pastilhas de hipoclorito após adição de etilenoglicol

\section{Onde encontrar os reagentes:}

O hipoclorito de cálcio é vendido em lojas de bricolage e jardim como desinfetante de piscinas, ou como lixívia em pó. Como referido no exemplo anterior, o etilenoglicol é vendido como anticongelante em lojas de artigos de automóvel.

\section{"Bomba" de fumo}

A capacidade de fazer fumo pode ser bastante útil em situações de sobrevivência, permitindo sinalizar pedidos de socorro, afugentar predadores ou confundir inimigos. O método mais comum de o fazer é colocar folhas verdes numa fogueira, mas na selva urbana isso nem sempre abunda. Este procedimento demonstra como preparar uma "bomba" de fumo, que pode ser transportada e ativada com segurança.

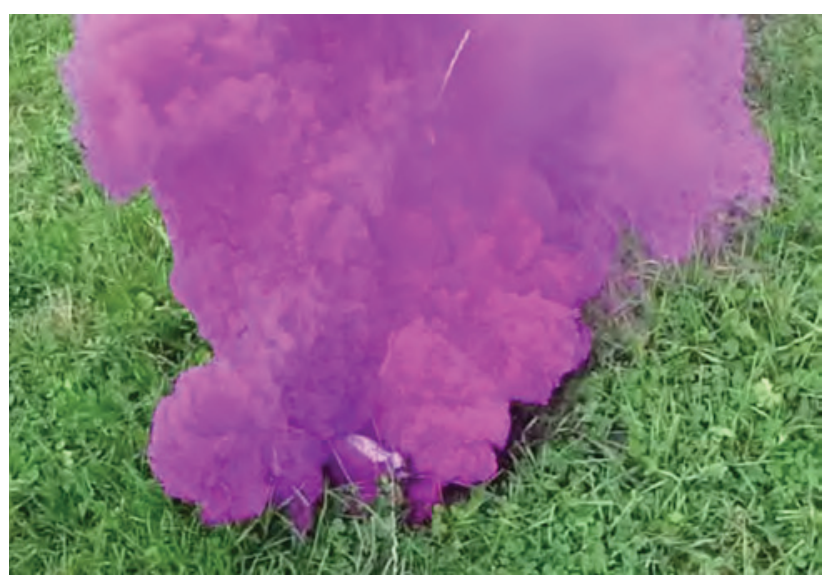

Figura 4 - Bomba de fumo colorido 
Para isso é necessário fazer uma mistura de sacarose, o açúcar que toda a gente conhece e do qual muitos abusam, com nitrato de potássio. Quando ateada, esta mistura queima muito rapidamente graças ao oxigénio presente no nitrato de potássio, libertando uma grande quantidade de vapor de água e cinza sob a forma de fumo [3].

$5 \mathrm{C}_{12} \mathrm{H}_{22} \mathrm{O}_{11}+48 \mathrm{KNO}_{3} \rightarrow 24 \mathrm{~K}_{2} \mathrm{CO}_{3}+36 \mathrm{CO}_{2}+55 \mathrm{H}_{2} \mathrm{O}+24 \mathrm{~N}_{2}$

\section{Material e reagentes:}

- Nitrato de potássio $\left(\mathrm{KNO}_{3}\right)$

- Açúcar (sacarose, $\mathrm{C}_{12} \mathrm{H}_{22} \mathrm{O}_{11}$ )

- Água

- Fonte de fogo

- Recipiente de alumínio

- Cordel de algodão

- Tubo de cartão ou de plástico

- Folha de alumínio

\section{Procedimento:}

- Misturar homogeneamente 30 g de açúcar com 70 g de nitrato de potássio.

- Testar a mistura, ateando uma pequena quantidade com um fósforo ou isqueiro. A mistura deverá queimar em poucos segundos com libertação de fumo.

- Colocar cerca de 70 g da mistura no tubo de cartão ou de plástico, assegurado que fica bem compactada. Tapar uma das extremidades com folha de alumínio. Este será o corpo da bomba de fumo, sendo agora necessário fazer um rastilho para que a ignição seja controlada e permita o afastamento do operador.

- Colocar 30 g da mistura no recipiente de alumínio e dissolver em 20 mL de água. É necessário ferver a solução para que a dissolução seja completa.

- Após dissolução total dos sólidos, desligar o aquecimento e adicionar o cordel de algodão para que este absorva todo o líquido.

- Cortar o cordel em pedaços de 10 a 15 cm, e deixar secar completamente ao ar. Cada pedaço será um rastilho que pode ser utilizado para montar a bomba, como exemplificado na Figura 5.

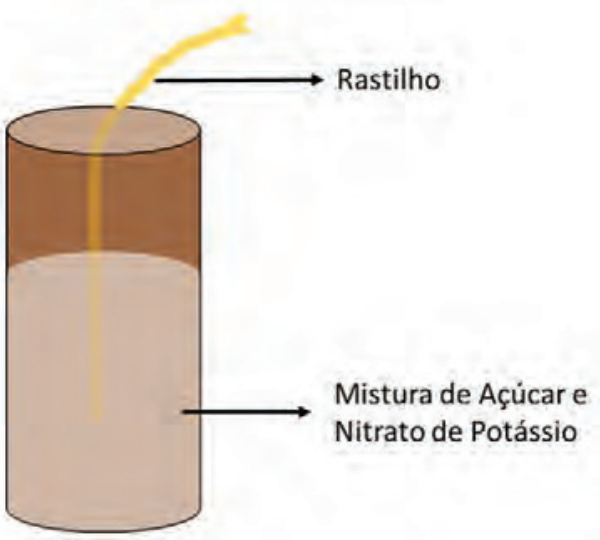

Figura 5 - Representação esquemática do corte longitudinal de uma bomba de fumo de açúcar e nitrato de potássio

\section{Onde encontrar os reagentes:}

O nitrato de potássio é vulgarmente vendido como adubo químico em lojas de horticultura ou como agente para remoção de cepos de árvore. O restante material é bastante fácil de encontrar, e pode aproveitar esta experiência para dar, finalmente, uso aos pacotinhos de açúcar que tem poupado no café.

Se pretender fazer bombas de fumo colorido, a mistura de açúcar e nitrato de potássio poderá ser combinada com lápis de cera de cor. Para isso, os três ingredientes deverão ser colocados num recipiente metálico e aquecidos até que a cera funda completamente.

\section{Carvão ativado}

O carvão ativado é simplesmente carbono no estado sólido com uma enorme área de superfície devido à sua elevada porosidade. Devido a esta característica, o carvão ativado tem a capacidade de adsorver uma grande quantidade de compostos orgânicos, tornando-o ideal para sistemas de filtragem e purificação de água. Para além disso, por ser quimicamente inerte, o carvão ativado pode ser tomado por via oral para tratar casos de envenenamento por ingestão. Desta forma, a capacidade de produzir esta substância com material acessível, poderá ser uma mais-valia em casos de sobrevivência.

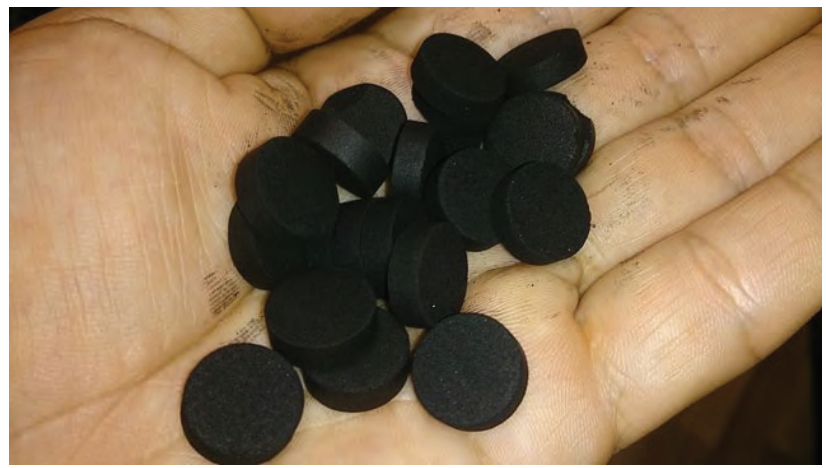

Figura 6 - Comprimidos de carvão ativado para usos medicinais

Para preparar carvão ativado a partir de matéria vegetal é preciso, em primeiro lugar, proceder à sua queima parcial. Isso é conseguido com uma fonte de calor que atinja os $400{ }^{\circ} \mathrm{C}$ e limitando a entrada de oxigénio. No final obtém-se apenas carbono e resíduos inorgânicos (cinza). Posteriormente, o carvão obtido deverá levar um tratamento químico, para que quaisquer resíduos solúveis sejam removidos e os poros fiquem acessíveis para adsorver compostos orgânicos [4].

\section{Material e reagentes:}

- Madeira ou outra matéria vegetal

- Recipiente de metal

- Cloreto de cálcio $\left(\mathrm{CaCl}_{2}\right)$

- Martelo

- Fonte de calor

\section{Procedimento:}

- Colocar um pedaço de madeira ou outra matéria vegetal no recipiente metálico, cobrir com folha de alumínio e levar ao lume durante 3 ou 4 horas.

- Depois de arrefecer, o carvão obtido deverá ser finamente esmagado com um martelo ou pedra.

- Preparar uma solução de cloreto de cálcio a 25\% (peso/ volume) e cobrir o carvão, deixando-o de molho durante 24 horas. 
- Decantar a solução de cloreto de cálcio e lavar o carvão com água. Secar no forno a $150{ }^{\circ} \mathrm{C}$ (ou em brasas de uma fogueira) até que fique bem seco.

Após estes passos, o carvão ativado estará pronto a usar. Poderá ser utilizado para filtrar água, fazer uma máscara anti-gás ou ser tomado para curar envenenamento por ingestão ou cólicas.

\section{Onde encontrar os reagentes:}

O cloreto de cálcio pode ser encontrado à venda como recarga em desumidificadores químicos em lojas de bricolage e decoração, ou em secções de tratamento de água para piscina. Em alternativa, pode-se utilizar ácido clorídrico (também vendido como ácido muriático) ou hidróxido de sódio (desentupidor de canos), desde que se tenha o cuidado de assegurar que o carvão é bem lavado após o tratamento químico.

\section{Biodiesel}

O biodiesel é um combustível que pode ser obtido a partir de óleo vegetal alimentar, pelo que tem ganho enorme popularidade nos últimos anos. Num cenário pós-apocalíptico, o biodiesel poderá desempenhar um papel importantíssimo, permitindo a deslocação em veículos motorizados ou a utilização de máquinas pesadas e de geradores elétricos. A sua preparação pode ser feita de um modo simples e com reagentes acessíveis. Do ponto de vista químico, a formação do biodiesel corresponde à transesterificação dos lípidos presentes no óleo, obtendo-se uma mistura de ácidos gordos esterificados e glicerol como produto secundário (Esquema 2). [5]

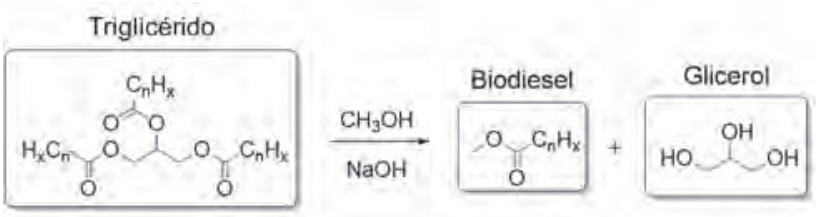

Esquema 2 - Reação de transesterificação dos triglicéridos do óleo vegetal

\section{Material e reagentes:}

- Óleo vegetal

- Metanol $\left(\mathrm{CH}_{3} \mathrm{OH}\right)$ ou etanol $\left(\mathrm{C}_{2} \mathrm{H}_{5} \mathrm{OH}\right)$

- Hidróxido de sódio $(\mathrm{NaOH})$

- 2 recipientes de vidro de $500 \mathrm{~mL}$

- Papel de filtro

\section{Procedimento:}

- Adicionar 2 g de hidróxido de sódio a 60 mL de álcool e agitar até que todo o sólido se dissolva

- Adicionar à solução cerca de $250 \mathrm{~mL}$ de óleo vegetal. No caso de se utilizar óleo vegetal velho, é recomendável a sua filtração com um papel de filtro ou um simples coador.

- Aquecer a mistura a $50{ }^{\circ} \mathrm{C}$ com agitação contínua durante uma a duas horas.

- Deixar a mistura arrefecer à temperatura ambiente e repousar algumas horas, o que deverá resultar na separação de duas fases (Figura 7).

- Decantar a fase superior (biodiesel) para um novo recipiente e adicionar cerca de $50 \mathrm{~mL}$ de água. Agitar le- vemente durante 1 minuto e deixar que a mistura se separe novamente em duas fases.

- Recolher a fase superior e filtrar para um recipiente limpo. Deixar o biodiesel aberto ao ar para que toda a água residual evapore.

Para além do biodiesel, este procedimento permite obter ainda glicerol, que corresponde à fase inferior. Este composto pode ser utilizado como lubrificante em diversas aplicações, para fazer sabonete ou ainda para atear um fogo, como demonstrado em experiências anteriores.

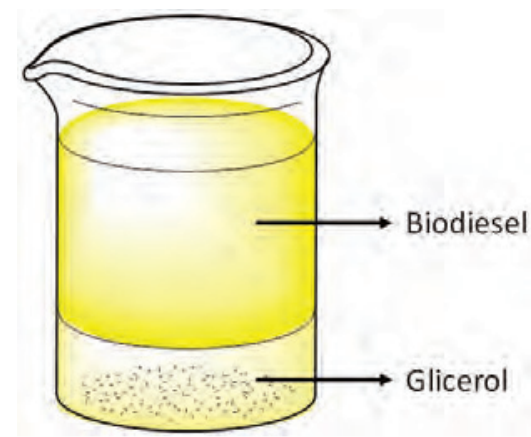

Figura 7 - Representação esquemática da separação da mistura reacional em duas fases após arrefecimento à temperatura ambiente

\section{Onde encontrar os reagentes:}

Para além do óleo vegetal que é de fácil aquisição, os restantes compostos podem ser encontrados em drogarias. O hidróxido de sódio é vulgarmente vendido como desentupidor de canos, e o metanol pode ser encontrado como diluente ou, por vezes, como anticongelante ecológico. Em alternativa, pode-se utilizar o etanol vendido nas farmácias.

\section{Pilhas}

Após uma catástrofe, uma das comodidades cuja falta se fará mais sentir, depois do Facebook e restante internet, é, sem dúvida, o fornecimento de energia por corrente elétrica. Apesar de, muito provavelmente, não precisarmos de bateria nos nossos smartphones, a utilização de pequenas pilhas poderá ser útil para nos manter iluminados e permitir ligar alguns aparelhos ou ferramentas. No entanto, a abundância das pilhas comuns deverá diminuir rapidamente após o colapso da sociedade, e é importante conhecer métodos alternativos para obter energia a partir de meios não convencionais.

\section{Pilha de moedas}

Num cenário pós-apocalíptico é expectável que o conceito de dinheiro mude radicalmente. Sem máquinas de

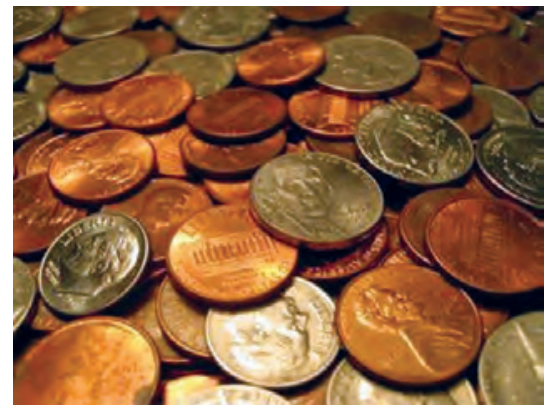

Figura 8 - Moedas secretamente a armazenar energia elétrica 
café, parquímetros e vending machines, é natural que as moedas percam a sua utilidade e relevância financeira. No entanto, as suas propriedades químicas mantêm-se inalteradas, e as moedas podem ser utilizadas para gerar corrente elétrica.

Das moedas de que dispomos na Europa, as mais indicadas para este tipo de aplicação são as de 1 a 5 cêntimos, compostas por aço com uma camada de cobre. Se as juntarmos com outro metal com um diferente potencial de redução, é possível promover uma reação química que resulta num fluxo de eletrões. Um dos metais mais comuns no nosso quotidiano é o alumínio, presente sob forma de folha ou na maioria das latas de conserva ou refrigerante, e pode ser utilizado no fabrico de pequenas pilhas com moedas.

\section{Material:}

- Moedas de 1, 2 ou 5 cêntimos (Cu)

- Folha ou tira de alumínio (Al)

- Sumo de limão ou vinagre (eletrólito)

- Pedaço de cartão ou esponja

\section{Procedimento:}

- Cortar o alumínio e o cartão ou esponja em quadrados ou círculos com dimensões aproximadas às das moedas a utilizar. Se se utilizar folha de alumínio, deverá dobrá-la de modo a obter uma espessura de cerca de $1 \mathrm{~mm}$ (aproximadamente 4 camadas).

- Molhar o cartão ou esponja na solução de eletrólito.

- Montar a pilha em camadas. O alumínio e a moeda devem ficar separados pelo cartão (ou esponja) (Figura 9).

Quimicamente, o que acontece nesta montagem é a oxidação do alumínio com libertação de eletrões (ânodo), que reduzem os protões presentes no eletrólito junto do cobre das moedas (cátodo) [6].

$$
\begin{aligned}
& \mathrm{Al} \rightleftharpoons \mathrm{Al}^{3+}+3 \mathrm{e}^{-} \\
& 2 \mathrm{H}^{+}+2 \mathrm{e}^{-} \rightleftharpoons \mathrm{H}_{2}
\end{aligned}
$$

Cada célula deverá gerar aproximadamente 0.5 V. Para obter uma maior diferença de potencial e poder ligar alguns dispositivos, várias destas células podem ser ligadas em série. Os terminais da pilha montada podem ser ligados com fio elétrico ou pedaços longos de folha de alumínio a um LED ou multímetro de modo a verificar o funcionamento da pilha.

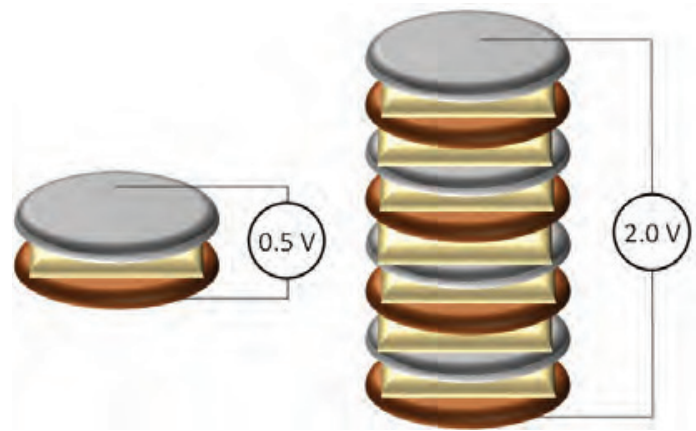

Figura 9 - Representação esquemática de células galvânicas compostas por alumínio e moedas de cobre

\section{Onde encontrar o material:}

Aproveitando os trocos espalhados no bolso do casaco, o alumínio que embrulhou a sandes do snack matinal, um guardanapo e água da torneira ou restos de refrigerante, é possível fazer uma destas pilhas.

\section{Pilha de alumínio/ar}

Outra alternativa para preparar uma pilha a partir de material do dia-a-dia, é a partir da reação de oxidação do alumínio com o oxigénio do ar [7].

$$
4 \mathrm{Al}(\mathrm{s})+3 \mathrm{O}_{2}(\mathrm{~g})+6 \mathrm{H}_{2} \mathrm{O}(\mathrm{l}) \rightarrow 4 \mathrm{Al}(\mathrm{OH})_{3}(\mathrm{~s})
$$

Mais uma vez a folha de alumínio revela-se bastante útil em situações de sobrevivência.

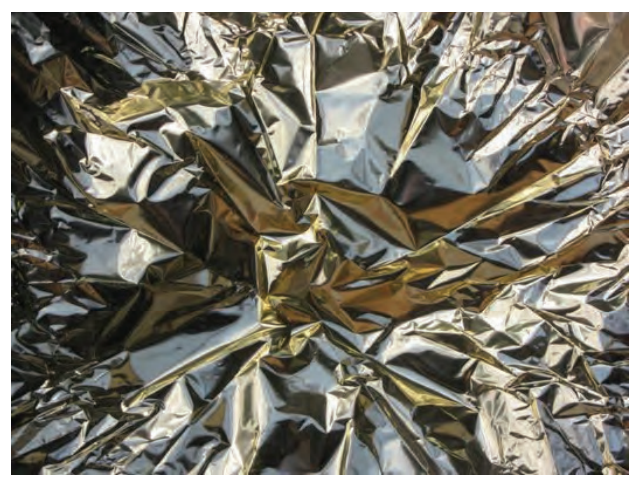

Figura 10 - A bem conhecida e útil folha de alumínio

\section{Material:}

- Folha de alumínio (Al)

- Solução de água com sal de cozinha $(\mathrm{NaCl})$

- Pedaço de cartão ou esponja

- Carvão ativado em grânulos

\section{Procedimento:}

- Cortar o alumínio em quadrados largos (cerca de 10 $\mathrm{cm}$ ), e o cartão ou esponja em quadrados ligeiramente mais pequenos.

- Molhar o cartão ou esponja na solução de sal.

- Partir ligeiramente o carvão ativado em pedaços de 3-4 mm.

- Montar a pilha em camadas de acordo com a Figura 11. Nesta montagem, o carvão ativado, para além de ser um bom condutor, favorece a reação com o oxigénio do ar devido à sua elevada área de superfície. Dependendo da área de alumínio e carvão utilizados, esta pilha deverá gerar perto de $1 \mathrm{~V}$ e $0.1 \mathrm{~A}$, sendo por isso suficiente para ligar um pequeno motor ou lâmpada/LED.

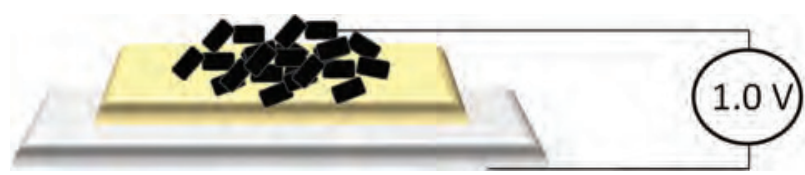

Figura 11 - Representação esquemática de uma pilha galvânica construída com folha de alumínio e carvão ativado

\section{Nota de segurança}

Caso o leitor esteja com vontade de treinar para cenários pós-apocalípticos, deverá ter em conta os perigos associados aos procedimentos aqui descritos. Alguns dos reagentes utilizados são perigosos e podem provocar queimaduras (hidróxido de sódio, permanganato de potássio e hipoclorito de cálcio). Por esta razão, recomenda-se o uso de material de proteção adequado (óculos de segurança, luvas e bata). 
Para além disso, as reações que permitem fazer fogo podem ser imprevisíveis e as chamas produzidas podem tomar dimensões não esperadas, pelo que deverão ser testadas apenas no exterior longe de qualquer material inflamável.

\section{Considerações finais}

Com conhecimentos básicos de química, que muitas vezes caem no esquecimento, é possível superar alguns desafios de sobrevivência com reagentes e materiais relativamente abundantes no nosso quotidiano. Este artigo descreve apenas alguns de imensos procedimentos que dão uma nova perspetiva ao modo como olhamos para os produtos do dia-a-dia e como os podemos utilizar para melhorar situações adversas. Desde a ubíqua folha de alumínio às indesejadas moedas "escuras”, passando por óleo usado ou pelo "cloro" de piscina, vários produtos escondem um potencial enorme para o comum mortal, mas não para o químico bem preparado. Quer se acredite ou não que o fim do mundo está próximo, “o saber não ocupa lugar” e vale a pena estar preparado e lembrar estas simples experiências.
Como o leitor deverá ter reparado, a grande maioria dos compostos utilizados nestas experiências pode ser encontrada em grandes superfícies de bricolage, decoração e jardim. Por isso, se a sua casa se encontra a poucos minutos de distância, não se preocupe, pois estará bem situado para enfrentar uma possível catástrofe que abale o funcionamento da sociedade como a conhecemos.

\section{Referências}

[1] H.C. Snyder, "The Extraordinary Chemistry of Ordinary Things”, John Wiley \& Sons, 2002.

[2] K.P. Kirkbride, H.J. Kobus, J. Forensic Sci. 36 (1991) 902 $-907$.

[3] M.S. Russel, “The Chemistry of Fireworks”, RSC Pub., 2009.

[4] A. Ahmadpour, D.D. Do, Carbon 35 (1997) 1723-1732.

[5] V.C. Eze, A.P. Harvey, A.N. Phan, Fuel 140 (2015) 724-730.

[6] D.J. Swartling, C. Morgan, J. Chem. Educ. 75 (1998) 181$-182$.

[7] S. Yang, J. Power Sources 112 (2002) 162-201.

\section{Atualidades Científicas}

\section{$\mathrm{FeBi}_{2}$ descoberto}

Avanços recentes em técnicas de alta pressão têm proporcionado aos químicos o estudo de sistemas cuja existência é, eventualmente, apenas possível naquelas condições. Esses novos recursos permitem, por exemplo, revisitar sistemas binários em busca de compostos que se mostraram inacessíveis até hoje. Um dos sistemas mais tentadores é aquele em que dois elementos não interagem, mesmo quando fundidos, os chamados sistemas imiscíveis. Um dos exemplos conhecidos é a imiscibilidade entre o ferro e o bismuto. Até à publicação deste trabalho não eram conhecidos compostos com ligações Fe-Bi.

Recentemente, uma equipa de investigadores liderada por Danna Freedman, da Universidade Northwestern, Evanston, EUA, sintetizou o primeiro composto binário de $\mathrm{Fe}$ e $\mathrm{Bi}, \mathrm{FeBi}_{2}$, recorrendo a pressões extremamente elevadas (> $30 \mathrm{GPa}$ ) e a uma temperatura de $1500 \mathrm{~K}$. O composto, que cristaliza numa estrutura semelhante ao $\mathrm{Al}_{2} \mathrm{Cu}$, é ainda detetável quando a pressão é diminuída até $3 \mathrm{GPa}$. De acordo com os investigadores, a abordagem da utilização de altas pressões pode ser uma via para a obtenção de novos materiais intermetálicos com ligações químicas nunca antes observadas no estado sólido.

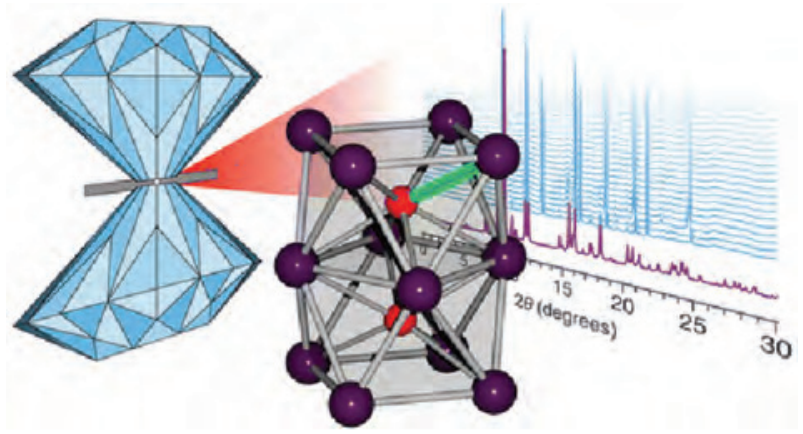

\section{Fontes:}

$\mathrm{FeBi}_{2}$ Discovered, http://www.chemistryviews.org/details/news/10015681/FeBi2_Discovered.html (Acedido em 10/11/2016)

J. P. S. Walsh, S. M. Clarke, Y. Meng, S. D. Jacobsen, D. E. Freedman. Discovery of FeBi $\mathbf{2}_{2}$ ACS Cent. Sci. 2 (2016) 867-871. DOI: 10.1021/acscentsci.6b00287 